\title{
Development of International-mindedness and Preferences for World Music in Teacher Preparation Coursework
}

\author{
Sharri K. VanAlstine ${ }^{1}$, Alena V. Holmes ${ }^{2}$ \\ ${ }^{1}$ University of Wisconsin-Whitewater, Whitewater, USA \\ ${ }^{2}$ University of Wisconsin-Whitewater, Whitewater, USA \\ Correspondence: Sharri VanAlstine, University of Wisconsin-Whitewater, CA2021, 800 West Main Street, Whitewater, \\ WI, 53545, USA.
}

Received: September 12, 2016

Accepted: September 29, $2016 \quad$ Online Published: October 18, 2016

doi:10.11114/jets.v4i11.1874

URL: http://dx.doi.org/10.11114/jets.v4i11.1874

\begin{abstract}
In higher education we aspire to prepare students to develop international-mindedness suited to become world citizens. The purpose of this study is (1) to investigate the development of international-mindedness during students' participation in music methods coursework and (2) to find out how international-mindedness is related to preference for world music. Results indicate that participants grew in the characteristics of international-mindedness as well as in their preference for a wide variety of world music examples by the end of the semester.
\end{abstract}

Keywords: international-mindedness, music education, music preferences, world music

\section{Introduction}

Globalization and increased diversity within the student population has resulted in a growing interest toward international and multicultural education. The National Standards for Music Education require that students experience the music of other cultures; however, the content of the programs vary in depth and in the quality of execution. Some teachers exhibit resistance to teaching music from diverse cultures due to personal bias, personal preference, and/or a lack of expertise and educational background (Teicher, 1997). In recent years universities have started paying more attention to internationalization on college campuses and the vital role played by faculty members in the internationalization of the curriculum (Bond, Qian, \& Huang, 2003). The necessity to make university courses more internationally and culturally relevant arises from the recognition that we have a responsibility to prepare all of our students for life in an increasingly diverse, interconnected, and interdependent world. There has been a focus on preparing teachers to be culturally sensitive to the needs of ethnically diverse classrooms, but it is equally important to prepare all students for life in the whole world, not only in the classroom (Craft, 1996). Research studies indicate that culturally responsive teaching is a promising approach to improving the academic achievement of culturally diverse students (Gay, 2001); therefore, it should be a fundamental element of teacher preparation and classroom practice (Gay \& Kirkland, 2003).

Despite the growing trend toward increasingly diverse classrooms around the world, the teaching workforce remains largely homogenous across a number of regions, especially in the USA (Capella- Santana, 2003). Many studies have been conducted investigating possible resolutions for the problem. Some research indicates that teachers can be trained through a variety of forms to overcome their culturally-based biases and become more sensitive, multicultural, flexible, and open-minded in their thinking and teaching (Razzano, 1996; Hayden et al., 2000; Thompson, 2007; Capella-Santana, 2003). Higher education institutions need to enable their graduates to possess a high degree of international-mindedness - well suited to live and work in a variety of cultural environments and places in the world as interculturally knowledgeable and responsible citizens.

\subsection{Development of International Mindedness}

The notion of international-mindedness figures prominently in the education discourse of international schools and the International Baccalaureate (IB) program. According to the IB deputy director general Ian Hill (2007), an integral part of an internationally-minded education includes understanding that people of different backgrounds hold different views, and students need to learn how to appropriately examine what they believe and why they believe as they do. This is 
what leads to understanding and respecting another perspective without necessarily adopting it. Furthermore, "mindedness" in international-mindedness is about empathy, not just knowledge. It is greater than what can be taught in a particular class; instead, it should be embedded in the whole school curriculum, both in and out of the classroom. Hett (1993), defines people who are internationally- or globally-minded as those who "possess an ecological world view, believe in the unity of humankind and the interdependence of humanity, support universal human rights, have loyalties that extend beyond national borders, and are futurists".

According to Haywood (2007), international-mindedness has five characteristics that all children need: (a) a curiosity and interest in the human and physical geography of earth, (b) an openness to different cultural approaches (tolerance), (c) a scientific understanding that the earth is valuable and common to everyone, (d) awareness that people are interrelated, and (e) respect for differing cultural backgrounds. The theoretical framework for this study stems primarily from Haywood's (2007) definition of international-mindedness. According to the International Baccalaureate Organization, (IBO) "We promote intercultural understanding and respect, not as an alternative to a sense of cultural and national identity, but as an essential part of life in the 21st century."

Helms' (2004) study employed the multicultural competency questionnaire, as well as the intercultural development inventory, which is based on the developmental model of intercultural sensitivity developed by Bennett in 1986 (as cited in Helms). The multicultural competency questionnaire revealed that coursework and immersion in other cultures have the greatest impact on the development of intercultural competence during students' graduate study. Helms also found that travel was the most widespread response with respect to the development intercultural competence amongst teaching faculty. Living in another country was also identified as having a considerable impact on one's own cultural sensitivity. Hosseinali (1995) conducted a study with forty-eight respondents from the College of Education at the University of Arkansas. He conducted two multiple regression analyses to correlate participants' demographic variables with levels of world-mindedness and global-mindedness. He found that gender, teaching experience abroad, and living outside the United States were all significant predictors for world-mindedness.

In addition, research indicates that individuals who speak more than one language experience the world differently from individuals who are monolingual, because 'important concepts and ways of thinking about the world - culturally specific modes of thinking - are embedded in language' (Razzano, 1996). Razzano attempts to describe the changes that occurred in American teachers who had spent some time living overseas before returning to the USA. Overall, they felt a much stronger commitment to finding innovative ways to make the educational process meaningful and useful to all of their diverse students, whereas before the overseas trips they focused primarily on pedagogy and thought little about intercultural difference.

Capella-Santana (2003) followed fifty-two American teachers through their training program to explore changes in multicultural attitudes and knowledge. She investigated how attitudes about curriculum, stereotypes, bilingual education, culturally related behaviors, building minority pupils' self-esteem, and assimilation of minority pupils into US culture changed across time. The last four areas of investigation were found to have significantly changed over the course of the study. The largest change was found to occur after participants had just completed a course and internship in multicultural education in culturally diverse settings.

Rodway's (2008) research on international-mindedness suggests that the most influential factors on the development of international-mindedness are travel, family, and education. Travel experiences are most significant when the traveler is immersed into the local culture in a foreign environment. Ideally, it would be best to provide our children with opportunities to travel and study abroad. Realistically, however, it is a not a common practice in American education. Families are also very influential in the development of international-mindedness, especially those who have lived abroad and families that have recently immigrated to the USA. According to Rodway's findings students who grow up in rural communities have limited experience with people of different cultures. Education is also an influential factor, and could be the primary factor, especially for students growing up in a largely monocultural environment. This is where the influence of teachers and schools is critical. Cultural exposure during school years, as well as international content, becomes powerful tools in the development of international-mindedness.

\subsection{World Music Preferences}

A number of researchers have examined students' preferences and familiarity for music of other cultures. Research findings indicate that musical preference is affected by several factors. Familiarity, musical characteristics, and students' characteristics have a significant effect on students' preference and attitudes for music (Brittin, 1996; Droe, 2006; Fung, 1996; LeBlanc et al., 2000; LeBlanc et al., 2002; Montgomery, 1996). From these considerations, music educators can create lessons that expand students' musical preferences and attitudes. Fung (1994b) explored the relationship between world music preferences and attitudes of undergraduate, non-music majors. After listening to randomized excerpts from Africa, China, India, Indonesia, Japan, Korea, the Middle East, and Thailand, participants responded on a 7-point 
Likert-type scale for music preference. Fung discovered that social and cultural attitudes affect world music preference and that students preferred instrumental musical styles above vocal musical styles. In a subsequent study, Fung (1996) investigated the relationship between musical characteristics and musicians' and non-musicians' preferences for world music. Results indicated that musical characteristics played a significant role in world music preference ratings. Fung specified that "the entire sample $(\mathrm{N}=449)$ preferred excerpts that were characterized as relatively fast, having many different pitches, tonal-centered, consonant, bright timbre, smooth, loud, complex or moderately complex in texture, and moderate in the richness of embellishment" (p. 71).

Holmes and VanAlstine's research (2014) with pre-service teachers $(\mathrm{N}=85)$ provided insights into the participants' familiarity and preference for world music samples. They were also asked to respond to survey items designed to measure international-mindedness. Findings indicate there is a significant difference between music education and elementary education majors' preference for world music. Music education majors preferred the world music examples to a significantly greater degree than did their elementary education counterparts. Interestingly, there was not a significant difference between groups for familiarity with world music - only with preference for world music. Furthermore, there were significant correlations between preferences and international-mindedness.

Shehan (1984) indicated that active instructional methods - such as emphasizing performance through singing and playing instruments - may increase students' preferences for the world music style students are currently learning to a greater extent than other methods (e.g., lectures, visual media, and guided listening). Burton (1986) suggested that active participation may be of particular importance in world music instruction as it provides students with opportunities to develop a greater appreciation for the unique musical processes employed in the performance of specific world music styles. Volk (1998) asserts "educators tend to agree that what is currently missing, and is most needed for music students, at this point is performance opportunities in a wide variety of cultures." Results of a study by Flowers (1980) indicates that musical activities such as analysis, performance, directed listening, and extra musical information increased college students' preference for specific African music selections to a greater extent than mere exposure; however, the increase in preference did not transfer to selections the students were not taught. Results of the Holmes and VanAlstine (2013) study indicate that even during a short period of instruction (a six-day summer choir camp), when middle and high school students study and perform world music, their international-mindedness grows, and they develop more positive attitudes about world music and the cultures from which they come.

Fung, (1997) after conducting research involving college students, recommended that transfer of world music preference from taught to untaught pieces may occur if (a) the instructional period is extensive and intense, (b) various teaching approaches are used, and (c) instruction includes in-class and out-of-class assignments and activities.

\subsection{Internationalized Approach to Instruction}

Pondering how to move students towards greater international-mindedness, the authors implemented eight strategies of an Internationalized Approach to Instruction (IAI).

Table 1. Strategies of an Internationalized Approach to Instruction

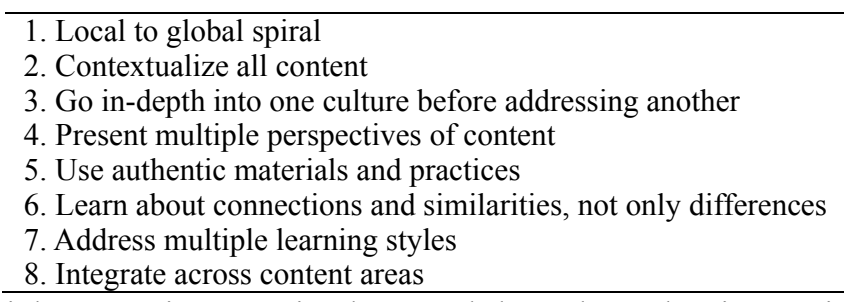

As shown in Table 1, these eight strategies were implemented through teacher instruction, modeled, and discussed in class. In addition, students developed and taught their own music lesson plans using the strategies of an IAI to frame their content and pedagogy.

VanAlstine (2011) found that pre-service teachers value learning about, and implementing, an internationalized approach to instruction. They indicated their confidence grew in their planning and teaching as they prepared lesson plans using the strategies and "trying them out" on their peers. They especially appreciated the depth with which they engaged with the music and content of the culture they each selected. The depth and breadth of their research gave them greater confidence in their own understanding and engagement with the culture and its music, further empowering them to plan authentic lessons and implement meaningful musical activities within the cultural context and content.

Pre-service elementary classroom teachers are often required to take a music methods class to obtain teacher licensure. This population will impact the entire next generation of children, and they typically have a wide experience with and preference for music and music education. With the critical role they will play in the lives and development of children, 
it is important that their development of international-mindedness is extensive and transferrable. Although there has been studies (Fung 1994a, 1994b, 1996, 1997; Shehan 1984) related to world music preferences, how an intentional approach to internationalized instruction and how it affects preference for world music is a new research trajectory. The purpose of this study, therefore, is to determine how an internationalized approach to instruction and the use of world music in the participants' requisite music methods course impacts their development of international-mindedness. The following research questions guided the study: 1. How does an internationalized approach to instruction affect the development of international-mindedness in the music methods coursework of pre-service elementary teachers? 2. How is preference for world music affected by an internationalized approach to instruction in the music methods coursework of pre-service elementary teachers? 3. Is there a relationship between preference for world music and the development of international-mindedness?

\section{Method}

In this cross-sectional survey (Plano-Clark \& Creswell, 2008) study pre-service elementary teachers $(\mathrm{N}=31)$ provided insights into their preference for world music samples through pre- and post-test listening examples. They were also asked to respond to survey items designed to measure international-mindedness. All participants were elementary education majors at a mid-sized university in the upper midwest region of the United States. The listening "test" and survey instrument was administered as a pre-test to all participants on their first day of class in the 2014 fall semester and again as a post-test at the end of the semester.

Using the international-mindedness instrument from a study by Baker and Kanan (2005) as the a starting point, survey items were created with alterations more accurately reflecting the content of the music course in which the participants were enrolled. The survey included two sections. The first section was largely demographic in nature, including fifteen questions regarding gender, musical background, birthplace, their parents' birthplace, where they have lived, and questions about the cultural background of friends and teachers. Part two included thirty questions related to the characteristics of international-mindedness. Participants responded to each of these items by marking their responses on a continuum.

Table 2. Haywood's Characteristics of International-Mindedness with Item Alignment

Characteristics of International-mindedness

Survey Items Aligned

\begin{tabular}{ll}
\hline a) curiosity and interest in the world around us related to the human and physical geography of & $14,17,23,26,35,36,40$ \\
the earth & $14,18,20,24,25,29,30,32,38$, \\
b) open attitudes to other cultural approaches & 42 \\
& $15,22,27,39$ \\
& $16,28,34,41$ \\
c) understanding scientifically that the earth is a valuable entity common to everyone & $19,21,31,33,37,43$ \\
d) recognition that people are interconnected & e) respect for other cultural backgrounds - situated in concern for the welfare of all people.
\end{tabular}

The items in part two of the survey were created in alignment with the definition of international-mindedness by Haywood (2007). Haywood's (2007) definition of international-mindedness indicates there are five characteristics of international-mindedness that can be included in the curriculum and assessed, including: a) curiosity and interest in the world around us related to the human and physical geography of the earth, b) open attitudes to other cultural approaches/tolerance, c) understanding scientifically that the earth is a valuable entity common to everyone, d) recognition that people are interconnected, and e) respect for other cultural backgrounds - situated in concern for the welfare of all people. Table 2 includes Haywood's (2007) international-mindedness characteristics and how they align with the items in Part Two of the survey.

Internal reliability of the items related to international-mindedness was addressed using Cronbach's alpha coefficient. Survey items related to the international-mindedness measures (thirty items in section two) were tested. Cronbach's alpha coefficient is in the acceptable range $(\alpha=.92)$ for the international-mindedness measures (A. Field, 2005; Pallant, 2007).

Victor Fung's World Music Preference Rating Scale (1994a) was used as the model to create the music listening preference instrument. The items on this instrument were aligned to measure participants' preferences for twenty-six world music excerpts of varying styles from West Africa, Eastern Europe, Western Europe, China, Indonesia, India, Latin America, and the Middle East. All of the musical examples represented traditional folk music and used musical instruments of the original cultures. The excerpts included only small ensemble sizes of two to four instruments. Each excerpt was played for approximately 50 to 60 seconds in random order, one after the other. All of the excerpts were selected from textbooks: Soundscapes: Exploring Music in Changing World (Shelemay, 2006), Excursions to World Music (Nettl et al., 2012), and from the Global Music Series (Bohlman et al., 2011) - all with input and suggestions 
from a musicology/ethnomusicology professor. Students listened to the musical examples and answered rated their preferences for each excerpt using a Likert-type scale. The researchers used the same musical examples from the same CDs for the pre- and post-test.

Internal reliability of the items on the world music preference test was also addressed using Cronbach's alpha coefficient. Cronbach's alpha coefficient is in the acceptable range $(\alpha=.90)$ for preference of the world music excerpts, as well (A. Field, 2005; Pallant, 2007).

The treatment was the use of an internationalized approach to instruction - both as an instructor and as part of the curriculum. The pre-service teachers were introduced to the strategies of an internationalized approach to instruction (Table 1) as the instructor taught utilizing these guidelines. Ultimately, once the strategies of an internationalized approach to instruction were introduced and modeled, all the student assignments for the remaining eight-nine weeks of the semester were constructed to utilize the strategies. For instance, the pre-service teachers selected a culture from which all of their analysis, research, planning, and teaching for the remainder of the semester would stem. They selected culturally authentic and relevant musical activities, analyzed the music and performance practices, researched the cultural and historical norms and milestones, and taught their activities and lessons to their classmates. The pre-service teacher' capstone project was writing a lesson plan integrating music with another content area based on their selected culture, framed by the strategies of an internationalized approach to instruction. The pre-service teachers taught their lessons to their peers. Following all of the lessons, the pre-service teachers reflected upon their own learning as well as the lessons in which they participated with their peers.

\section{Results}

A paired-samples T-test was conducted to evaluate the development of international-mindedness from the pre-test at the beginning of the semester to the post-test at the end. There was a statistically significant increase in international-mindedness for each of the five characteristics of international-mindedness described by Haywood (2007). For instance, there was a statistically significant increase in international-mindedness from pre-test $(M=3.74, S D=$ 1.03 ) to the post-test $(M=4.37, S D=.72), t(29)=-3.275, p=.003$ (two-tailed) on survey question twenty. The eta squared statistic (.28) indicated a large effect size.

Table 3 includes the descriptive statistics for the remaining survey items pertaining to international-mindedness and how they align with the characteristics of international-mindedness. The items that showed a significant growth from pre- to post-test are italicized.

Table 3. Descriptive Statistics for Items Aligned with International-Mindedness Characteristics

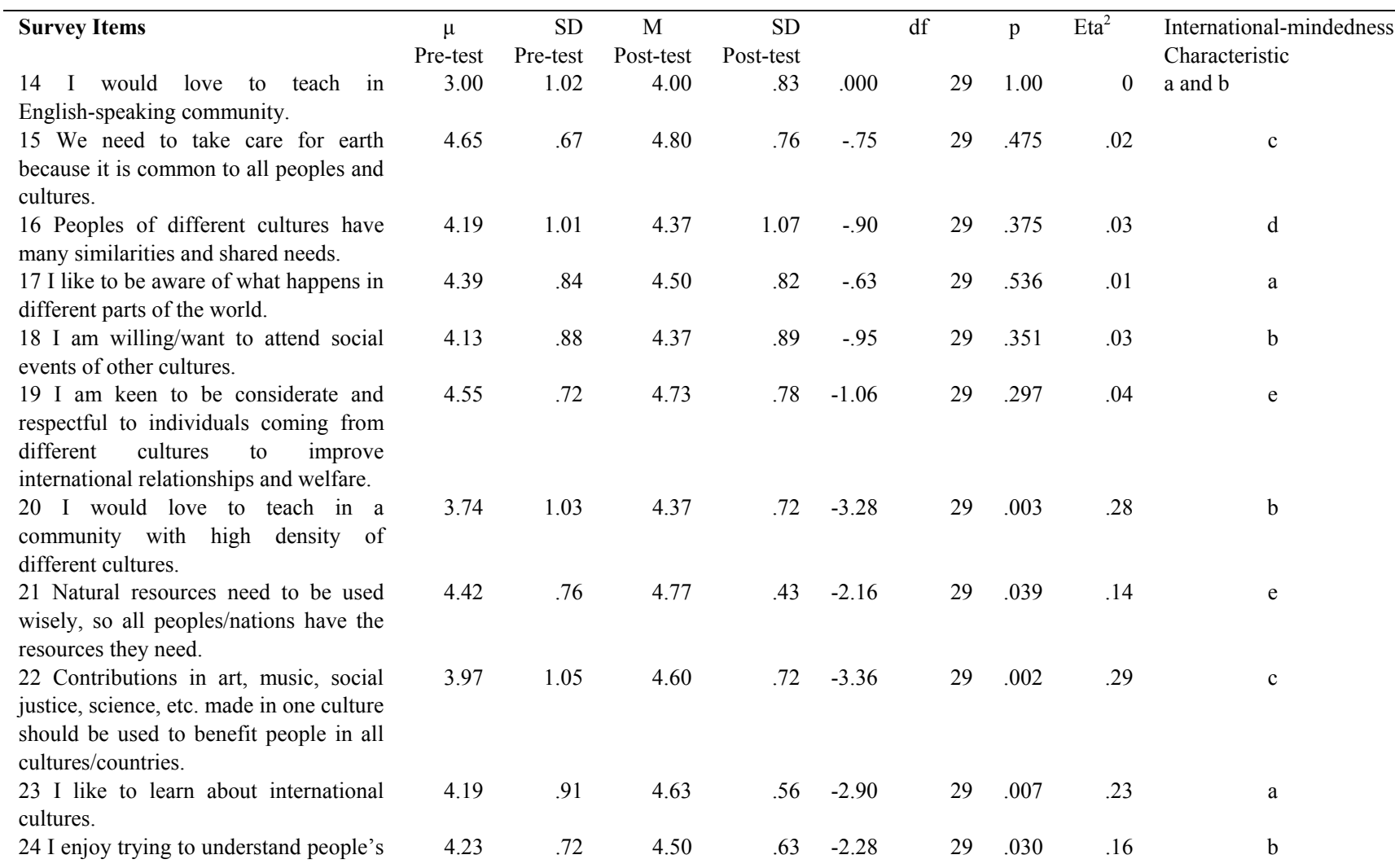


behavior in the context of their culture. 25 I do not believe any culture is superior to any other culture.

26 I would consider student teaching in an international school if I could afford to do so.

27 How I treat the environment can have a positive or negative impact on people in other parts of the world.

28 I think of myself not only as a citizen of my country, but also as a citizen of the world.

29 Schools should teach history of the whole world rather than of our country only.

$30 \mathrm{I}$ am interested to know about other beliefs and points of view

31 I believe that a person should respect other perspectives even if they are different from their own perspective in an effort to improve the conditions of people around the world

32 I would consider teaching in an international school during career.

33 People who have the largest proportion of the world's resources have an obligation to share their wealth with the less fortunate peoples of the world.

34 My behavior can have an impact on people in other countries

35 I generally find it stimulating to spend an evening talking with people from another culture.

36 Receptive of people from different religions or different cultures

37 The fact that a flood can kill 50,000 people in another country is very depressing to me.

38 I respect students' cultural traditions even if they negatively impact curriculum and outcomes.

39 I need to influence others to take care of the environment because it has an impact on everyone and every country.

40 I like to watch/read the news and keep up with what is happening around the world.

41 I am able to have an impact on what happens on a global level by what I do in my own community.

42 I can learn things of value from people of different cultures.

43 When I see the conditions in which

\begin{tabular}{|c|c|c|c|c|c|c|}
\hline 4.58 & 4.83 & .46 & -1.42 & 29 & .165 & .06 \\
\hline 4.06 & 4.20 & .96 & -.49 & 29 & .630 & .01 \\
\hline 4.61 & 4.83 & .38 & -1.49 & 29 & .147 & .07 \\
\hline 4.26 & 4.67 & .48 & -2.85 & 29 & .008 & .23 \\
\hline 3.97 & 4.50 & .90 & -2.25 & 29 & .032 & .17 \\
\hline 4.35 & 4.60 & .62 & -1.37 & 29 & .182 & .06 \\
\hline 4.71 & 4.93 & .25 & -1.56 & 29 & .129 & .08 \\
\hline
\end{tabular}




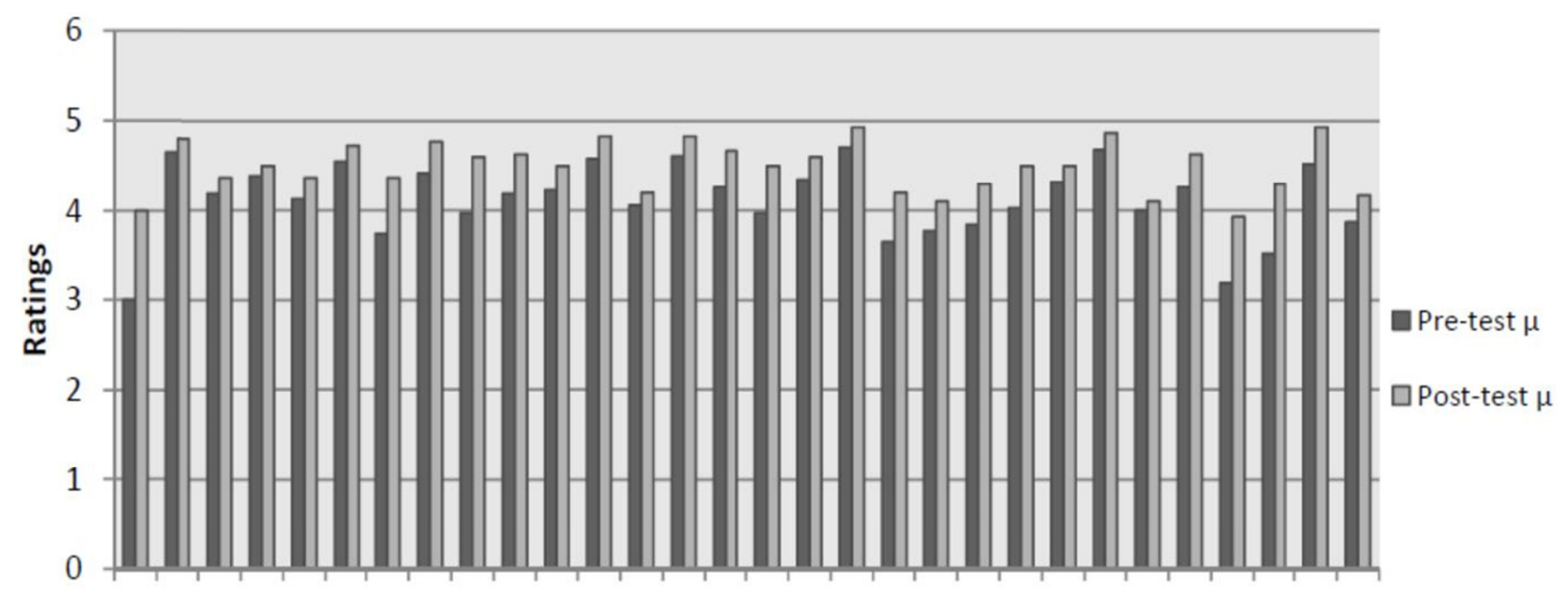

141516171819202122232425262728293031323334353637383940414243

\section{Survey Items}

Figure 1. Pre- and Post-test Mean Scores for Survey Items Related to International-Mindedness

Figure 1 includes the pre- and post-test $\mu$ scores for the survey items related to international-mindedness. There was an increase on all thirty items pertaining to the development of international-mindedness, although not all of the increases reached significance as indicated in Table 3.

A paired-samples t-test was conducted to evaluate the participants' preferences for world music samples from the pre- to the post-test - rating each example on a Likert-type scale from 1 ("Strongly Dislike") to 7 ("Strongly Like"). Each example was played for 50-60 seconds, one at a time. After students heard the excerpt, they rated it for their preference, and the next example was played. Results indicate there was a statistically significant increase in preferences for $24 \%$ of the listening examples. For instance, there was a statistically significant increase in preference from pre-test $(M=5.69$, $S D=.76)$ to the post-test $(M=6.10, S D=.77), t(29)=-3.041, p=.005$ (two-tailed) on selection two - a Latin American piece. The eta squared statistic (.25) indicated a large effect size.

Table 4 includes the remaining survey items pertaining to world music preferences for the rest of the results of the paired-samples T-Test. The music examples that the participants indicated a significant growth in preference from preto post-test are italicized. 
Table 4. World Music Examples Pre-Post Test on a Scale of 1-7 (1=Strongly Dislike \& 7= Strongly Like)

\begin{tabular}{|c|c|c|c|c|c|c|c|c|}
\hline World Music Music Example & $\underline{\text { Pre- } \mu}$ & $\underline{\text { Pre- SD }}$ & $\underline{\text { Post- } \mu}$ & $\underline{\text { Post- SD }}$ & $\underline{t}$ & $\underline{d f}$ & $\underline{p}$ & $\underline{E t a^{2}}$ \\
\hline West Africa & 5.0 & .93 & 5.38 & 1.32 & -1.95 & 28 & .062 & .13 \\
\hline Latin American & 5.69 & .76 & 6.10 & .77 & -3.04 & 28 & .005 & .25 \\
\hline Middle Eastern & 4.48 & 1.15 & 4.79 & 1.26 & -1.88 & 28 & .071 & .11 \\
\hline Greek & 4.83 & 1.23 & 5.24 & 1.18 & -2.86 & 28 & .008 & .23 \\
\hline Indonesian & 4.28 & 1.31 & 4.69 & 1.20 & -1.99 & 28 & .056 & .12 \\
\hline Middle Eastern & 4.24 & 1.21 & 4.52 & 1.55 & -1.98 & 27 & .058 & .12 \\
\hline West African & 3.75 & 1.55 & 4.00 & 1.70 & -1.37 & 27 & .183 & .06 \\
\hline Latin American & 5.00 & 1.31 & 5.50 & 1.14 & -3.33 & 27 & .002 & .29 \\
\hline \multirow[t]{2}{*}{ Middle Eastern } & 4.21 & 1.17 & 4.61 & 1.26 & -2.65 & 27 & .013 & .21 \\
\hline & 3.61 & 1.20 & 3.86 & 1.46 & -1.43 & 27 & .165 & .07 \\
\hline \multicolumn{9}{|l|}{ Chinese } \\
\hline Chinese & 4.00 & 1.05 & 4.29 & 1.24 & -1.61 & 27 & .118 & .09 \\
\hline Bulgarian & 3.54 & 1.07 & 4.29 & 1.24 & -2.88 & 27 & .008 & .13 \\
\hline Russian & 4.14 & 1.04 & 4.68 & 1.16 & -2.84 & 27 & .009 & .23 \\
\hline West African & 3.93 & 1.33 & 3.75 & 1.40 & .895 & 27 & .379 & .03 \\
\hline Indian & 3.93 & 1.30 & 4.29 & 1.80 & -1.04 & 24 & .306 & .04 \\
\hline Indonesian & 3.79 & 1.57 & 3.71 & 1.84 & .328 & 27 & .745 & .00 \\
\hline West African & 4.64 & 1.37 & 5.07 & 1.12 & -1.76 & 27 & .090 & .10 \\
\hline Indian & 4.54 & 1.26 & 4.29 & 1.46 & 1.32 & 27 & .199 & .06 \\
\hline Indonesian & 2.14 & .93 & 2.21 & 1.55 & -.258 & 27 & .798 & .00 \\
\hline Latin American & 5.36 & .99 & 5.25 & 1.27 & .441 & 27 & .663 & .01 \\
\hline Chinese & 3.61 & 1.10 & 3.46 & 1.48 & .626 & 27 & .537 & .01 \\
\hline Middle Eastern & 3.93 & 1.25 & 4.00 & 1.49 & -.290 & 27 & .774 & .02 \\
\hline Indonesian & 3.14 & 1.43 & 3.18 & 1.66 & -.150 & 27 & .882 & .00 \\
\hline Indian & 3.39 & 1.34 & 3.43 & 1.50 & -.130 & 27 & .897 & .00 \\
\hline Chinese & 3.36 & 1.34 & 3.39 & 1.34 & -.135 & 27 & .894 & .00 \\
\hline Indian & 2.04 & .74 & 1.96 & 1.04 & .493 & 27 & .626 & .01 \\
\hline
\end{tabular}

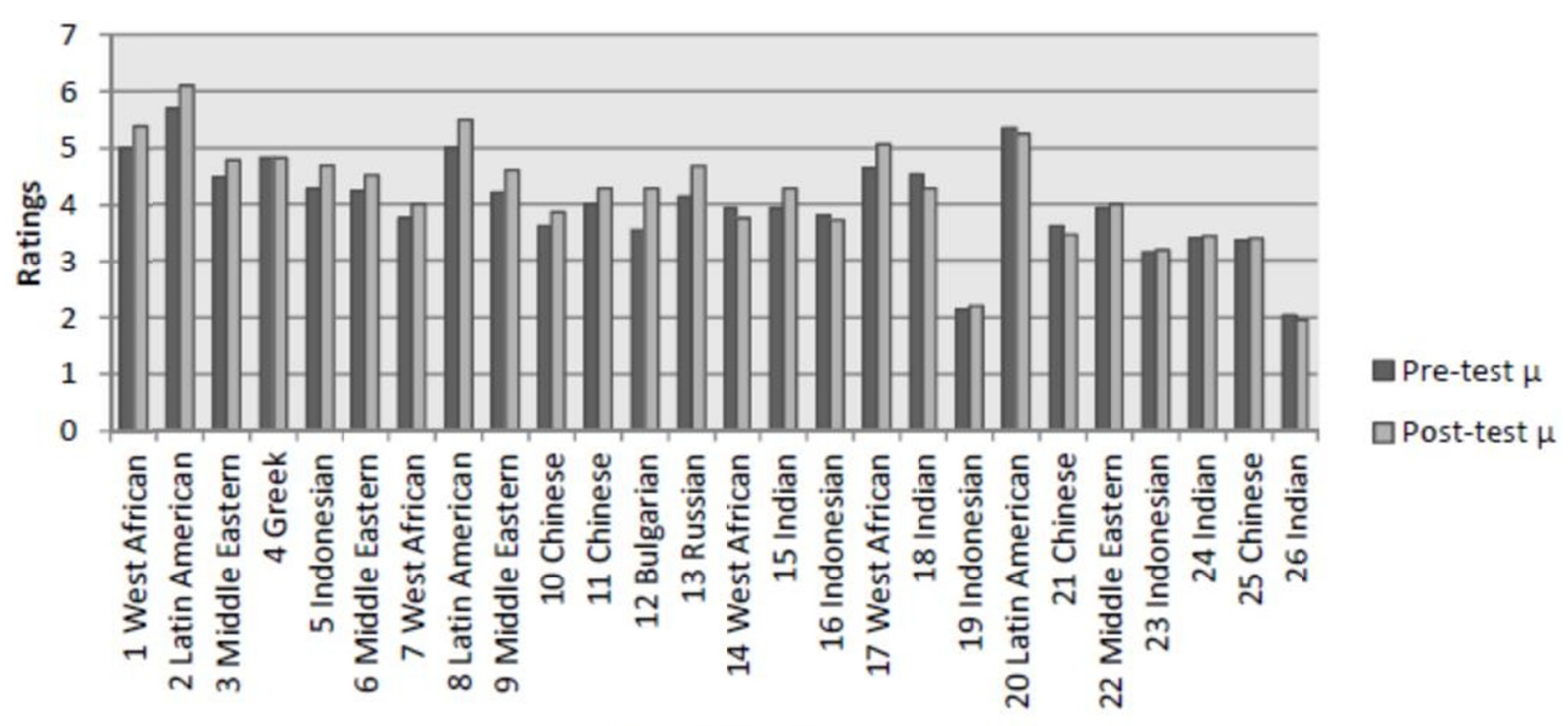

Music Examples

Figure 2. Pre- and Post-test Mean Scores for World Music Examples

Participants rated eighty-one percent of the music examples higher on the post-test hearing than on the pre-test hearing. There was a significant increase for twenty-four percent of the listening examples from the pre- to the post-test. All of these pairings were rated "like" or "strongly like" on both pre- and post-test - they simply liked them more on the post-test. For instance, the ratings of Example 2 from Latin America - pre-test $\mu=5.69$, post-test $\mu=6.10$. There was 
also a decrease in preference for nineteen percent of the examples. None of the decreases, however, were significant, and none of the decreases went below the middle of the Likert scale towards "dislike." For instance, the ratings of Example 20 from Latin America - pre-test $\mu=5.36$, post-test $\mu=5.25$. The highest preference ratings were for two West African, three Latin American, and one Greek piece. The lowest ratings on both pre- and post-tests included two Indonesian, one Indian, and one Chinese piece. Although these ratings were lowest, and below the middle of the Likert scale toward "dislike," none of the ratings of these four pieces decreased from pre- to post-test. Figure 2 includes the pre- and post-test $\mu$ scores for preference for the world music examples.

The relationship between the international-mindedness survey items and the world music examples was investigated using Pearson product-moment correlation coefficient. There were no strong correlations, and only a few small or moderate correlations.

A MANOVA was conducted to determine whether world music examples had a significant main effect for the development of international-mindedness. There was no significant main effect for world music examples and the development of international-mindedness. Likewise, a MANOVA was conducted to determine whether international-mindedness had a significant main effect for the preference for world music. There was no significant main effect for international-mindedness and preference for world music examples.

\section{Discussion}

The most significant result of this study was in the development of international-mindedness. The participants grew in international-mindedness on all five of Haywood's (2007) characteristics throughout the semester. It cannot be determined that the treatment caused the growth, but the growth was evident in the survey responses and in the quality of the assignments the pre-service teachers completed during the semester. The participants developed activities and lesson plans using an internationalized approach to instruction, and the scores on their assignments increased by $14 \%$ by the end of the semester. The increases reflected a greater grasp on all aspects of planning, including the use of an internationalized approach to instruction. They gained greater understanding, and it was reflected in the final lesson plans they created, taught, and the depth of their subsequent reflections.

Participants also indicated growth in their preference for a wide variety of world music examples. Their preference grew for eighty-one percent of the music examples on the post-test compared to their scores on the pre-test. Twenty-four percent of those increases were a significant increase from pre- to post-test. Although there does not seem to be strong correlations between the characteristics of international-mindedness, it appears the participants' preferences for world music grew in a similar fashion to their growth in the development of international-mindedness. Their added appreciation for world music may have developed through their own study of new or unfamiliar musics in the context of their culture for their own lessons. For instance, their lesson planning included in-depth research and analysis of a chosen culture and its musical practices. For their final lesson plan, each participant chose a musical piece and/or activity to integrate with another content area from their chosen culture - a culture for which they had spent the bulk of the semester investigating and planning lessons and activities. Furthermore, they may have also gained greater appreciation for world musics as they participated in the lessons their classmates had spent an equivalent amount of time and work researching, analyzing, and creating.

It is interesting that there is not a strong correlation between the international-mindedness characteristics and the world music examples. More research, therefore, needs to be done into what created the rise in both international-mindedness and preference for world music. Perhaps their development of international-mindedness can more accurately be attributed to their research related to their chosen culture and the lessons they planned and taught based upon those cultures. This would seem to indicate that the development of international-mindedness could be fostered in our future educators as they grapple with the strategies used to internationalize a lesson. Concentrated effort on one culture throughout most of the semester certainly increased student understanding of their culture and its artistic habits as well as gave them greater confidence to teach about their chosen culture in a meaningful, true, and authentic manner. It appears that the exposure and implementation of the internationalized strategies is effective in the development of international-mindedness. If this is the case, perhaps the strategies will have an equally positive effect on the development of international-mindedness in other content areas in addition to music methods coursework.

The inclusion of world music throughout individual assignments as well as the exposure the pre-service teachers had through the lessons and activities their peers shared may have been the experience they needed to develop greater appreciation for world music. All participants were required to select a culture for which they were somehow connected for their lesson and activity planning and instruction. They could choose a culture from their own family history, one in the region in which the university is situated, or one in which they were particularly interested and had a primary source for gaining greater insight.

Generally, their ratings of the world music examples indicate they tended to like the pieces that were more rhythmic in 
nature, and especially those that utilized functional harmony. The pieces that utilized other tuning systems, unfamiliar musical techniques, or unmetered rhythm were least favorably rated. Furthermore, none of the students selected unmetered or non-diatonic pieces for any of their lessons or activities. The world music examples they heard on the survey, however, included both unmetered/metered, diatonic/non-diatonic, and a variety of indigenous instruments and timbres. Their preferences became quite clear as they selected music that fell into the realm of metered, diatonic, and common western timbres. Their ratings of all others fell below the mid-point of the Likert scale toward "dislike." Interestingly, very few students selected cultures in which unmetered and non-diatonic music is common. This may be a reflection of their own cultural heritage or a reflection of the cultural heritages common in the area of the country in which they live. If experience and exposure can positively impact their development of international-mindedness and their preference for world music, class time and content invested into the cultures in which they were more unfamiliar may be the next step in their development of international-mindedness and preference for their currently "unpreferred" world musics.

Although study abroad and cultural immersion are ideal ways in which to development international-mindedness (Rodway, 2008) it is helpful to note that the development of international-mindedness is within the grasp of all teacher educators providing methods instruction on a localized campus. This class was not part of a study abroad program. It is not focused on immersion into a local "world" culture which can be very expensive and time-consuming in a crowded teacher education curriculum. Furthermore, not every university is located in an area surrounded by authentic and in-depth multi-cultural opportunities. The internationalizing strategies used in the class - both in terms of instructor approach/content and student assignments-have significantly increased the participants' development of international-mindedness. This indicates that one class in a four-year degree program can have a positive impact on the development of international-mindedness. In a teacher-preparation course, it may even indicate that these future teachers will utilize the international-mindedness characteristics and strategies in their own future planning and teaching.

Finally, this study indicates pre-service elementary teachers like "some" world music. Further research into what makes the music itself "preferred" would be helpful - particularly with the general elementary classroom teacher. They teach children so many aspects of culture that a meaningful understanding and appreciation for the music of our vast array of cultures may significantly and authentically enhance their curriculum. With this information, teacher educators will be better informed in regards to world music content for teacher preparation. Paired with concentrated study of a culture, using internationalized teaching strategies may translate to the elementary classroom - where this generation of elementary classroom teachers inspire and guide the next generation of world citizens and budding musicians.

\section{References}

Baker, A. M., \& Kanan, H. (2005). International mindedness of native students as a function of the type of school attended and gender: The Qatari case. Journal of Research in International Education, 4(3), 333-349. http://dx.doi.org/10.1177/1475240905057813

Bohlman P., Capwell C., Dueck, B., Nettl B., Rommen, T., Turino T., \& Wong, I. K. F. (2011). Excursions in world music. New Jersey: Prentice-Hall, Inc.

Bond, S., Qian, J., \& Huang, J. (2003). The role of faculty in internationalizing the undergraduate curriculum and classroom experience. CBIE Research Millennium Series No. 8. Ottawa, Ontario, Canada: Canadian Bureau for International Education.

Brittin, R. V. (1996). Listeners' preference for music of other cultures: Comparing response modes. Journal of Research in Music Education, 44, 328-340. http://dx.doi.org/10.2307/3345445

Burton, L. H. (1986). Commonalities in the musics of diverse cultures. International Society for Music Education Yearbook, 13, 111-118.

Capella-Santana, N. (2003). Voices of teacher candidates: positive changes in multicultural attitudes and knowledge. The Journal of Education Research, 96(3), 182-189. http://dx.doi.org/10.1080/00220670309598806

Craft, M. (1996). Cultural diversity and teacher education. In M. Craft (Ed.), Teacher education in plural societies: An international review (pp. 1-15). London: Falmer.

Droe, K. (2006). Music preference and music education: A review of literature. UPDATE: Applications of Research in Music Education, 24(2), 23-32. http://dx.doi.org/10.1177/87551233060240020103

Field, A. (2005). Discovering statistics using SPSS. Thousand Oaks, CA: Sage Publications Ltd.

Flowers, P. J. (1980). Relationship between two measures of music preference. Contributions to Music Education, 8, 47-54. 
Fung, C. V. (1994a). College students' preferences for world musics. Contributions to Music Education, 21, 46-63.

Fung, C. V. (1994b). Undergraduate nonmusic majors' world music preference and multicultural attitudes. Journal of Research in Music Education, 42, 45-57. http://dx.doi.org/10.2307/3345336

Fung, C. V. (1996). Musicians' and nonmusicians' preferences for world musics: Relation to musical characteristics and familiarity. Journal of Research in Music Education, 44(1), 60-83. http://dx.doi.org/10.2307/3345414

Fung, C. V. (1997). Effects of a world music course. The Minnesota Music Educators Journal, 53(3), 25-29.

Gay, G. (2001). Educational equality for students of color. In J.A. Banks, \& C. A. M. Banks (Eds.), Multicultural education: Issues \& Perspectives (pp. 197-224). New York: Wiley.

Gay, G., \& Kirkland, K. (2003). Developing cultural critical consciousness and self- reflection in preservice teacher education. Theory into Practice, 42(3), 265-276. http://dx.doi.org/10.1207/s15430421 tip4203_3

Hayden, M. C., Rancic, B. A., \& Thompson, J. J. (2000). Being international: Student and teacher perceptions from international schools. Oxford Review of Education, 26(1), 107-124. http://dx.doi.org/10.1080/030549800103890

Haywood, T. (2007). A simple typology of international-mindedness and its implications for education. In M. Hayden, J. Levy \& J. Thompson (Eds.), The Sage Handbook of Research in International Education (pp. 79-89). Thousand Oaks, CA: Sage Publications. http://dx.doi.org/10.4135/9781848607866.n8

Helms, S. M. (2004). The examination of cultural sensitivity and exhibition of cultural competence for faculty at liberal arts institutions within higher education. Dissertation Abstracts International, 64(10), 3609A. (UMI No. 3107769)

Hett, E. J. (1993). The development of an instrument to measure global-mindedness. Unpublished doctoral dissertation, University of San Diego.

Hill, I. (2007). International education as developed by the International Baccalaureate Organization. In M. Hayden, J. Levy \& J. Thompson (Eds.), The Sage Handbook of Research in International Education (pp. 25-37). Thousand Oaks, CA: Sage Publications Inc. http://dx.doi.org/10.4135/9781848607866.n3

Holmes, A., \& VanAlstine, S. (2013). World Music Immersion During Summer Choir Camp: Implications for the Development of International Mindedness, Attitudes, and Preferences in Middle/High School Choir Students. The Proceedings of the 2013 Desert Skies Symposium. University of Arizona, Tucson, AZ

Holmes, A., \& VanAlstine, S. (2014). Music education majors vs. elementary education majors: The relationship between world music preferences and international-mindedness. GSTF International Journal of Music, 1(1), 5-13. http://dx.doi.org/10.5176/2382-574x_1.1.2

Hosseinali, T. (1995). The relationship of globalmindedness to travel and living abroad experiences of university professors. Dissertation Abstracts International, 56(07), 2544. (UMI No. 9536034)

IBO (n.d.). Mission. Retrieved October 12, 2016 from http://www.ibo.org/about-the-ib/mission

LeBlanc, A., Fung, C. V., Boal-Palheiros, G. M., Burt-Rider, A., Ogawa, Y., Oliviera, A. J., ... (2002). Effect of strength of rhythmic beat on preference of young music listeners in Brazil, Greece, Japan, Portugal, and the United States.

LeBlanc, A., Young, C. J., Chen-Hafteck, L., De Jesus, O. A., Oosthuysen, S., \& Tafuri, J. (2000-2001, Winter). Tempo preferences of young listeners in Brazil, China, Italy, South Africa, and the United States. Bulletin for the Council of Research in Music Education, 147, 97-102.

Montgomery, A. P. (1996). Effect of tempo on music preferences of children in elementary and middle school. Journal of Research in Music Education, 44(2), 134-146. http://dx.doi.org/10.2307/3345666

Nettl, B., Rommen, T., Capwell, C., Wong I. K. F., Turino, T., Bohlman P., \& Dueck, B. (2012). Excursions in World Music. New Jersey: Pearson Education.

Pallant, J. (2007). SPSS survival manual: A step by step guide to data analysis using SPSS for Windows (3 ${ }^{\text {rd }}$ ed.). New York: Open University Press.

Plano-Clark, V. L., \& Creswell, J. W. (2008). The mixed methods reader. Thousand Oaks, CA: Sage Publications.

Razzano, E. (1996). The overseas route to multicultural and international education. The Clearing House, 69(5), 268270. http://dx.doi.org/10.1080/00098655.1996.10114314

Rodway, J. D. (2008). Making Sense of International Mindedness in the InternationalBaccalaureate Diploma Program. ProQuest Dissertations and Theses.

Shehan, P. (1984). The effect of instruction method of preference, achievement, and attentiveness for Indonesian gamelan music. Psychology of Music, 12, 34-42. http://dx.doi.org/10.1177/0305735684121004 
Shelemay, K. K. (2006). Soundscapes: Exploring Music in Changing World. New York, NY:W.W. Norton \& Company, Inc.

Teicher, J. M. (1997). Effect of multicultural music experience on preservice elementary teachers' attitudes. Journal of Research in Music Education, 45(3), 415-427. http://dx.doi.org/10.2307/3345536

VanAlstine, S. (2011). Pre-service elementary education teachers: An international approach to music methods coursework. (Doctoral Dissertation). Retrieved from ProQuest Dissertations and Theses. (Accession Order No. ATT 3466999)

VanAlstine, S., \& Holmes, A. (2014). The Effect of Course Content and Pedagogy on Undergraduate Students International-Mindedness and Preferences for World Music. 2014 NAfME Music Research and Teacher Education National Conference. Presentation conducted from National Association for Music Education, St. Louis, MO.

Volk, T. M. (1998). Music Education and Multiculturism. New York, NY: Oxford University Press.

This work is licensed under a Creative Commons Attribution 3.0 License. 